\title{
Perception Isn't Everything: The Reality of Class Size
}

\section{Mark Umbricht and Kevin Stange}

\section{About the Authors}

The authors are with the University of Michigan. Kevin Stange is also with the National Bureau of Economic Research.

\begin{abstract}
Acknowledgments
We would like to thank Paul Courant, Ben Koester, Steve Lonn, Tim McCay, and numerous participants in seminars at the University of Michigan for helpful comments. This research was conducted as part of the University of Michigan Institutional Learning Analytics Committee. The authors are solely responsible for the conclusions and findings.
\end{abstract}

\begin{abstract}
Every term, institutions of higher education must make decisions about the class size for each class they offer, which can have implications for student outcomes, satisfaction, and cost. These decisions must be made within the current higher education landscape of tightening budgets and calls for increased productivity. Beyond institution decision making, prospective students and their families may use class size as one factor in deciding whether an institution might be a good fit for them. The current measure of class size found in university fact books, and subsequently sent to numerous ranking groups such as U.S. News \& World Report (hereafter U.S. News), is an inadequate gauge of the student experience in the classroom, as measured by the percent of time students spend in classes of varying sizes. The current measure does not weight for enrollment, credits, or multiple components of a class, which results in a misleading representation of the student experience of class size. This paper will discuss these issues in depth, explain how class size varies across institutions, and offer recommendations on how to reweight class size in the Common Data Set to accurately describe it from the student's perspective. Institutions could use this new metric to better understand class size, and subsequently to understand the student experience and cost of a class, while prospective students and their families could use the metric to gain a clearer picture of the class sizes they are likely to experience on campus.
\end{abstract}

Keywords: class size, productivity, student outcomes

The AIR Professional File, Fall 2019

Article 146 https://doi.org/10.34315/apf1462019

(c) Copyright 2019, Association for Institutional Research 


\section{INTRODUCTION}

Organizing class delivery is a key operational decision for institutions of higher education. Each term these institutions must decide how many students will be taught within each section given the classes they offer, the faculty and instructors they have available to teach, and the confines of physical spaces they have on campus. Within these constraints, institutions must decide how to deliver classes. Consider a popular class taken by nearly every first-year student: Should this class be taught as one large lecture by a famous professor, many small sections taught by graduate students, or a combination of the two? Should small classes target freshmen who are acclimating to college or seniors as they specialize in their field?

Institutions, particularly public institutions, make these decisions within the current context of increased accountability and decreased resources. Traditional wisdom argues that smaller classes increase engagement, facilitate student-faculty interactions, and improve student success. The opportunity to learn from prominent scholars in the field is also considered a strength of undergraduate education at research universities. However, smaller classes and senior faculty are costlier and their use comes at the expense of other ways of enriching and supporting the undergraduate student experience. As Courant and Turner (forthcoming) argue, institutions have an interest in providing curriculum efficiently, meaning they must strike a balance between quality, costs, and tuition revenue. If an institution or department has an influx of students, it must decide whether it will increase the size of its faculty or the class size of its courses. Therefore, decisions about class size have first-order influence on student success and institutional costs. From the student perspective, class size could be influential in the college choice process, with some students seeking intimate class settings with small class sizes, and others preferring to blend in to a large classroom. Students and their families rely on institutional websites and rankings, such as Princeton Review or U.S. News, and other publicly available data for information about class size. These data are typically drawn from the Common Data Set (CDS), which is a collaborative effort among data providers and publishers to improve the quality and accuracy of information provided to prospective students, and to reduce the reporting burden on data providers (CDS Initiative, 2018). While it is helpful to have a measure that can be reported across multiple campuses, the class size metric used by the CDS is measured at the classroom level rather than at the student level. This difference in measurement leads to a disconnect between the metric and the phenomena it is trying to describe, as described in the following example.

Imagine a high school student researching her nearby public, research university as a prospective student. She sees that, according to U.S. News in 2018 , only $17 \%$ of classes have more than 50 students, and $57 \%$ of classes have fewer than 20 students. The student thinks, What luck! She thinks she can attend a high-quality research institution while spending most of her time in small classes. After graduation from that college, the same student looks back and sees that she spent more than $41 \%$ of her time in classes with more than 50 students, and only $20 \%$ of her time in classes with fewer than 20 students. These differences in the perception versus reality are not exaggerated, but rather are many students' average experience. This paper will show that the measure of class size calculated for the CDS, and subsequently used by many other sources, does not provide an accurate approximation of the true class size experienced 
by students at the University of Michigan (U-M), a large, research university in the Midwest. By the term "student experience," we mean the percent of time or credits spent in classes of varying sizes. The results of this case study could be replicated at any institution, with varying degrees of departure from the true student experience depending on the institution type and size. Specifically, this paper will argue for a new class size metric to be used in the CDS and will address the following questions:

\section{Framing Questions}

1| How does the standard definition of class size vary from the student experience?

2| How does a student-centric version of class size vary across an institution?

3| How can institutional researchers practically recalculate class size to better approximate the student experience without significantly increasing the burden of data providers?

\section{Importance of the Topic and Literature Review}

This topic is important for students, institutions, and the field of institutional research. From the student perspective, students and those assisting in their decisions need accurate and meaningful information to make the best decision about which college to attend. A small number of studies have shown that class size is an important factor for students as they select an institution (Drewes \& Michael, 2006; Espinoza, Bradshaw, \& Hausman, 2002). This makes sense since lower class size is perceived to be linked to gains in student outcomes. Literature in the secondary setting is clear that lower class size is associated with gains across multiple areas, including test scores, noncognitive skills, college enrollment, and other outcomes (Angrist \& Lavy, 1999; Chetty et al., 2010; Dee \& West, 2011; Dynarski, Hyman, \& Schanzenbach, 2013; Hoxby, 2000; Krueger, 1999). However, in higher education the relationship between class size and outcomes is not well established, with studies finding either negligible association (Bettinger, Doss, Loeb, Rogers, \& Taylor, 2017; Lande, Wright, \& Bartholomew, 2016; Stange \& Umbricht, 2018; Wright, Bergom, \& Lande, 2015) or a negative relationship between class size and outcomes (Bettinger \& Long, 2018; De Giorgi, Pellizzari, \& Woolston, 2012; Kokkelenberg, Dillon, \& Christy, 2008). Institutions that gain a more accurate and more nuanced version of class size from the student experience perspective could aid prospective students in their decision-making process.

Class size is also important to institutions for planning purposes. Courant and Turner (forthcoming) argue that institutions must strike a balance between quality, costs, and tuition revenue. In recent years, institutions have been asked to cut back and do more with fewer resources, which would imply that increasing class size would be an appropriate strategy. In fact, class size is one of the most important drivers of instructional costs (Hemelt, Stange, Furquim, Simon, \& Sawyer, 2018). However, lower class size is perceived to lead to better student outcomes and is subsequently tied to rankings such as those at U.S. News. This common perception pulls institutions to keep class size lower, putting institutions in a situation where a logical solution is to hire cheaper instructors, such as noncontingent faculty. The ultimate decision on how to strike this balance is not traditionally made at the institution level, but rather at the department level. Cross and Goldenberg (2009) found that the number of noncontingent faculty at elite research institutions rose significantly in the 1990s, which was due to 
micro- (department-)level decisions. Departments (or colleges) that are particularly concerned with the quality (or perceived quality) of small class sizes would find it difficult to adequately assess how much time their students spend in classes of a given size with the current metric, which is at the class level. A new student experience version of class size would allow departments to compare the class size experience across multiple majors or between departments, which could assist in balancing the class size constraints for long-term planning. Having an accurate understanding of imbalances by class size across colleges, departments, or majors could help institutions pinpoint areas that need improvement. In addition, institutions could examine whether access to smaller classes is inequitable across certain student groups, such as among minority, first-generation, or first-year students.

We will argue that the current definition of class size used in the CDS Initiative (2018) is insufficient for both internal planning and external consumption. As institutional researchers, it is our job to provide meaningful and accurate information to both internal and external parties. While the traditional measure of class size may be accurate, this paper describes ways in which we could provide data that are more meaningful. Institutional researchers and higher education professionals have an obligation to update this metric to reflect the actual student experience.

\section{DEFINING GLASS SIZE}

Based on the conventions of the CDS, undergraduate class size is calculated based on the number of classes with a given class size range. Classes are divided into sections and subsections.
A class section is an organized class that is offered by credit, is identified by discipline and number, meets at one or more stated times in a classroom or setting, and is not a subsection such as a laboratory or discussion section. A class subsection is a part of a class that is supplementary and meets separate from the lecture, such as laboratory, recitation, and discussions sections. In calculations of class size, we count only the sections of a class and discard the subsections. The CDS conventions consider any section or subsection with at least one degreeseeking undergraduate student enrolled for credit to be an undergraduate class section, but exclude distance learning, noncredit, and specialized oneon-one classes such as dissertation or thesis, music instruction, one-to-one readings, independent study, internships, and so on. If multiple classes are crosslisted, then the set of classes are listed only once to avoid duplication (CDS Initiative, 2018). This means that we count stand-alone classes, defined as having only one component, once per section in the class section portion.

For classes with multiple components, such as a lecture section combined with a lab or discussion section, we count each lecture section once in the class section portion while we count each associated lab or discussion section once in the class subsection table. In traditional class size metrics, the CDS counts only the class section portion of the class while the CDS discards the subsection from the calculation. This metric is relatively easy to compute and is comparable across campuses, but it may not be representative of the student experience.

We define "student experience class size" as the percent of time spent by a student in classes of various sizes, using credits as a proxy for time. ${ }^{1}$ Calculations for this metric will be discussed later in

1. We assume that each credit associated with a class is approximately 50 minutes of class time. While this pattern is not universal across $U$-M, the calculation is easy to make and should be readily accessible in any institution's data warehouse. A more complicated, but $100 \%$ accurate approach, would be to use the day and time location to derive the true number of minutes spent in each section. These data might not be accessible and would require substantial coding to calculate. We tested both approaches and our simplified approach did not meaningfully differ. 
Figure 1. Class Size by Various Sources

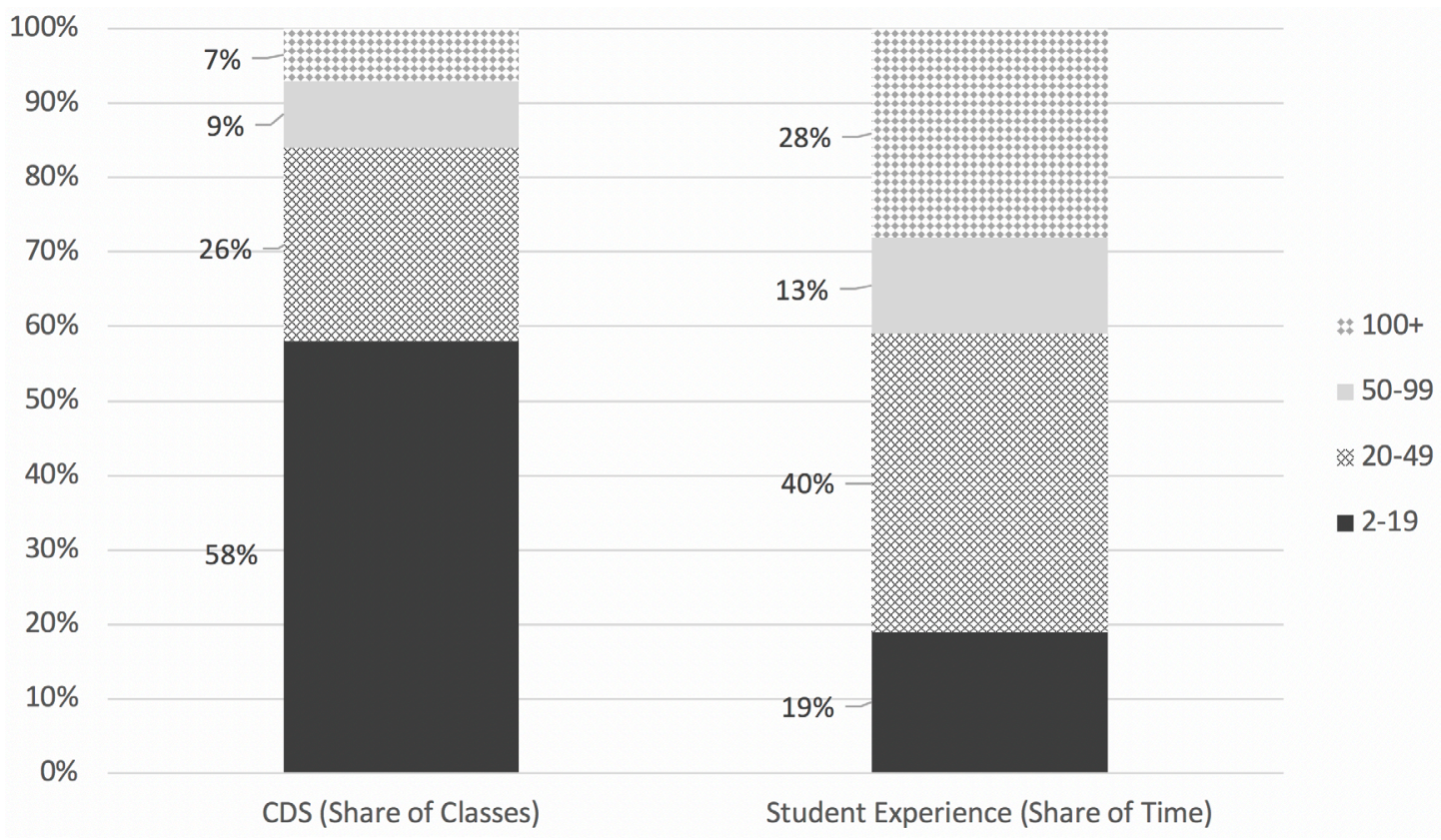

this paper. Figure 1 shows the difference between the CDS method and our new student experience method of computing class size. Sources that are often used as references for prospective students and institutions, such as U.S. News and institutional websites, draw data from the CDS. The CDS metric describes the share of classes in a given range rather than the share of time spent in classes of varying sizes. According to the U.S. News and the U-M websites, $84 \%$ of classes at U-M have fewer than 50 students, and 57\% have fewer than 20 students. However, using our student experience class size metric, only $19 \%$ of a student's classroom time is spent in classes with fewer than 20 students and nearly $30 \%$ of their time is spent in classes with at least 100 other students. Why do these metrics differ so drastically?
There are three primary reasons driving these differences. First, the traditional measure for class size is not weighted by the number of students enrolled. A 500-student section and a 5-student section both count as one class, even though many more students experience the larger section. Second, classes are not weighted by the number of credits associated with the class. A class worth five credits counts for the same as a class worth one credit, even though students likely spend five times as much time in the first class. Finally, the traditional measure does not incorporate subsections. It is typical for large lecture classes to have multiple components, such as a large lecture of 200 that meets for 2 hours per week and 10 associated small discussion groups of 20 students each that meet for 1 hour per week. Students spend $67 \%$ of their classroom time in a large lecture and 33\% of their time in a small discussion, but the traditional metric 
counts only the lecture portion. This means the 200-person lecture counts as one class, ignoring the subsections. Our new student experience class size metric accounts for these three factors, as will be explained in detail in the methods section. This new metric provides a more accurate representation of the student experience within the classroom.

Given the immense difference between the traditional class size measure and our student experience version, it is only natural to question why institutions have not moved to a different calculation of class size. To be clear, it is not the authors' belief that institutions are purposely trying to push an inaccurate measure of class size. The traditional class size measure does hold value in describing the number of classes available to students of various class sizes. U-M students can choose from many small classes and could theoretically construct a set of classes to minimize the amount of time spent in large classes. In reality, though, several forces could make it difficult for institutions to switch to a student experience version of class size.

First, there are serious consequences in rankings and optics for many institutions, particularly larger ones. U.S. News currently provides points to institutions based on the share of small sections (19 and fewer students), partial points for the share of medium sections (20-49 students), and no points for large sections (50 or more students). ${ }^{2}$ Universities that use larger class sizes to teach a large number of students will see their rankings negatively impacted if classes were weighted by the number of students taking the class. The shift in class size would also create poor optics for prospective students and may impact whether they choose one institution over another. The same would be true for a student experience measurement of instructor type, where larger research institutions are much more likely to use graduate students as instructors. In addition, having non-tenure track instructors primarily responsible for teaching large classes, and therefore many students, could have bad optics for institutions. Therefore, there is a disincentive for a single college, or a small group of colleges, to recalculate their class size based on the student experience. The exception would be institutions that uniformly have very small classes, such as small liberal arts colleges, that would see little or no change in their calculation of class size.

A second difficulty is measuring class size from the student perspective. Leaders of the CDS Initiative already consider the measurement of class size to be the second-most difficult part of the CDS, with only calculations of financial aid deemed more difficult (Bernstein, Sauermelch, Morse, \& Lebo, 2015). At U-M, measures required to recalculate class size to the student perspective are readily available and clean, and require little manipulation to combine. Institutions vary significantly in their data capacity and availability of staff to adjust the CDS measures. Given these challenges, the authors of this study still believe that shifting to a student experience version of class size would provide many benefits, including an accurate representation of the amount of time students spend in classes of varying sizes and with various instructor types. This shift would be beneficial for institutions for planning purposes as well as for prospective students as they weigh various institutions during the selection process.

2. This recently changed from a system that provided points for small courses and penalties for large courses in an effort to minimize gaming of the system (Supiano, 2018). However, there is no evidence provided to back up this claim. Regardless of whether the new or old system is used, having a larger number of small classes is rewarded, and the metric is at the course level, which does not appropriately describe the student experience. 
Table 1. Example of Distribution of Class Credits in Our Framework

\begin{tabular}{|c|c|c|c|c|c|c|}
\hline $\begin{array}{l}\text { Number of } \\
\text { Students }\end{array}$ & Class 1 & Class 2 & Class 3 & Class 4 & $\begin{array}{l}\text { Total } \\
\text { Credits }\end{array}$ & $\begin{array}{l}\% \text { of } \\
\text { Total }\end{array}$ \\
\hline \multicolumn{7}{|l|}{$2-9$} \\
\hline \multicolumn{7}{|l|}{$10-19$} \\
\hline $20-29$ & 1 (Lab) & 1 (Discussion) & & & 2 & $17 \%$ \\
\hline \multicolumn{7}{|l|}{$30-39$} \\
\hline $40-49$ & & & 3 (Lecture) & & 3 & $25 \%$ \\
\hline $50-99$ & & & & 2 (Lecture) & 2 & $17 \%$ \\
\hline $100-199$ & 2 (Lecture) & & & & 2 & $17 \%$ \\
\hline $200+$ & & 3 (Lecture) & & & 3 & $25 \%$ \\
\hline $\begin{array}{c}\text { Total } \\
\text { Credits }\end{array}$ & 3 & 4 & 3 & 2 & 12 & $100 \%$ \\
\hline
\end{tabular}

\section{METHODS}

The purpose of this study is to create a student experience version of class size. We drew data from the U-M data warehouse, specifically from the Learning Analytics Data Architecture (LARC) and College Resource Analysis System (CRAS). ${ }^{3}$ LARC is a flattened, research-friendly version of the raw data warehouse that houses data about students, their background, their progress, and their coursework. CRAS is a data warehouse system that houses data about classes and the instructors that teach them. The sample included first-time freshman students in cohorts between 2001 and 2012, examining classes taken within 4 years of entry. Freshman cohorts are between approximately 5,500 and 6,500 students during this period. Individual study classes and one- on-one classes were removed from the sample, as were classes with no CRAS information, including subjects such as medicine, dentistry, armed forces, study abroad, and classes through the Committee on Institutional Cooperation program. The final sample included 70,426 first-time students and 3,398,320 class sections taken in these students' first 4 years of study, between 2001 and 2016 .

\section{Calculating Class Size}

As previously noted, we made three adjustments to the traditional measure of class size: (1) weighting for number of students, (2) weighting for credits associated with the section, and (3) incorporating subsections. Table 1 provides an example of how

3. LARC is unique to U-M, although some institutions have developed a similar research-friendly database. CRAS is also unique to U-M because there are some calculations made with institution-specific formulas. However, these databases comprise data that are regularly available (although not always clean) at all institutions, such as student and class information, classes taken, and the number of students in a given class. 
we accounted for credits and subsections in our student experience framework.

This example shows a hypothetical student's coursework for one term. This student took four classes in this term for a total of 12 credits. Classes 1 and 2 had multiple components, with a lecture and either a discussion or a lab. We divided credits for these classes among the section and subsection based on the amount of time or credits associated with each component. Then we put each component into the appropriate class size bin, shown in the left column. Classes 3 and 4 were stand-alone classes that contained only a lecture component, so there was no need to divide their credits. Once we had distributed all the credits for each class to the appropriate class size bin, we totaled credits across each class size row. In doing so, we accounted for credits and the multicomponent nature of classes, fixing two of the issues with the standard definition of class size. The third piece relates to weighting class size by the number of students in the class. In this framework, we theoretically create a table like this for each student and each term the student attends. We then summed across every student and term. Since the level of observation is a class enrollment, we naturally weight by the number of students in the class because there will be 50 observations if there are 50 students in a class, or 5 observations for a class with 5 students. A basic assumption made by this framework is that one credit is equal to approximately 1 hour of class time. While there are a small number of classes that violate this assumption, we do not believe it would impact our overall results in a meaningful way. It is also important to note that enrollments for crosslisted classes were combined into the home class. At $U-M$, if there are multiple cross-listed sections, one is considered the home class and the rest are considered away classes. This means that if there are three cross-listed sections with 12,15, and 18 students, our data would show one class with 45 students.

Once we calculated the percent of time (using credits as a proxy) that a student earned in various class sizes across his first four years, we calculated percentiles for each enrollment group across the entire university by college, by major, and by year in school. ${ }^{4}$ College and major are determined by the last college or major associated with a student. If a student graduated with a bachelor's degree, we used his graduating college or major. If a student departed prior to completing his degree, we used the last known college and major associated with him. ${ }^{5}$ Rather than showing just the median or mean, we chose to use five percentiles (10th, 25th, 50th, 75th, and 90th) to show the distribution of student experiences. Finally, we mapped these percentiles into figures that show the range of student experiences for a given class size.

\section{CASE STUDY}

This section will examine how class size varies across $U$-M. The figures in this section represent the distribution of time that students spend in classrooms of varying sizes. Class size was grouped into eight bins of varying sizes to create a smooth figure and to mimic the traditional measure of class size. Figure 2 shows the distribution of class size across the entire university. The black line represents the median student, the dark gray shaded area represents the 25th to 75th percentile, and the light gray shaded area represents the 10th

4. Results show the 10th, 25th, 50th, 75th, and 90th percentile for each enrollment group. The term "college" refers to an academic college, such as engineering liberal arts and science, or education.

5. We considered removing these students but decided that doing so could introduce some selection bias. For example, students that drop out may select larger courses; if we remove them, we may distort the student experience. 
Figure 2. Percent of Time Spent by Size Across the University of Michigan

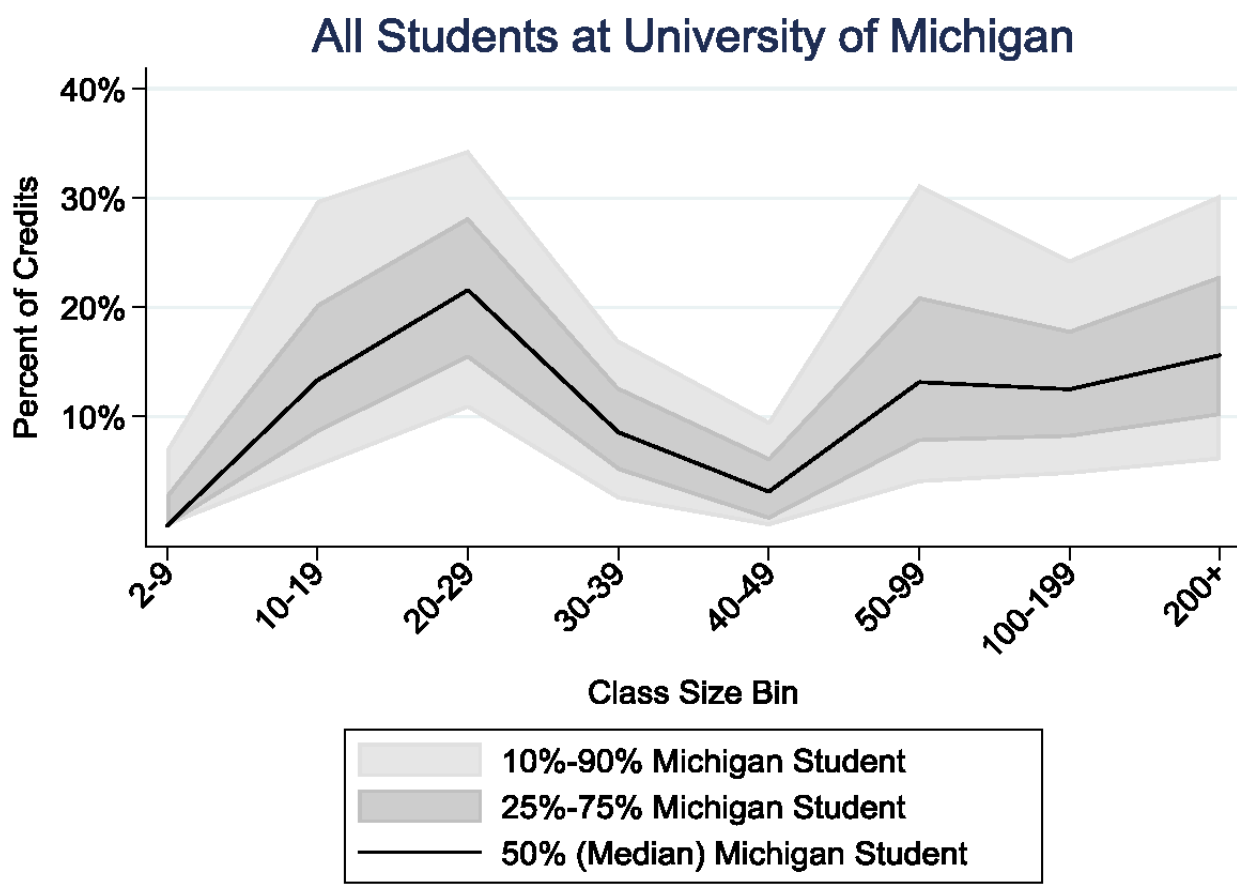

to 90th percentiles.

To interpret this figure, consider the enrollment group of $200+$ students. The black line indicates that the median U-M student spent about 15\% of her time in classes with 200 or more students. Moving above the black line to the edge of the dark gray area, we see that about a quarter of students spent about $23 \%-24 \%$ of their time in classes with 200 or more students. The outer edge of the light gray area indicates that $10 \%$ of students at U-M spent more than $30 \%$ of their time in these very large classes. If we move to the 20-29 enrollment group, we see that the median student spent about $20 \%$ of her time in classes with 20-29 students. There is a very wide range of experiences (25\%) between the 10th and 90th percentiles, indicating that students may spend vastly different amounts of time in classes with $20-29$ students. The spread is only about $10 \%$ wide for enrollment groups between 30 and 49 students, indicating there is less variability in the percent of time spent in medium-size classes. Overall, it is clear that students' time is more heavily weighted in both large (50+ students) and small (10-29 students) classes. This means that students spend their time in classes of varying sizes, but classes at U-M tend to favor high or low enrollments on average. This also implies that very large classes likely have a smaller enrollment component tied to them, such as a discussion or lab section.

At a university the size of $U-M$, with an undergraduate population of almost 30,000, it is natural to assume that student experiences may vary greatly across the institution, such as by college, major, or year in school. Figure 3 shows the distribution of class size in the College of Engineering, which we chose because it is the 
Figure 3. Percent of Time Spent by Enrollment Group in the College of Engineering

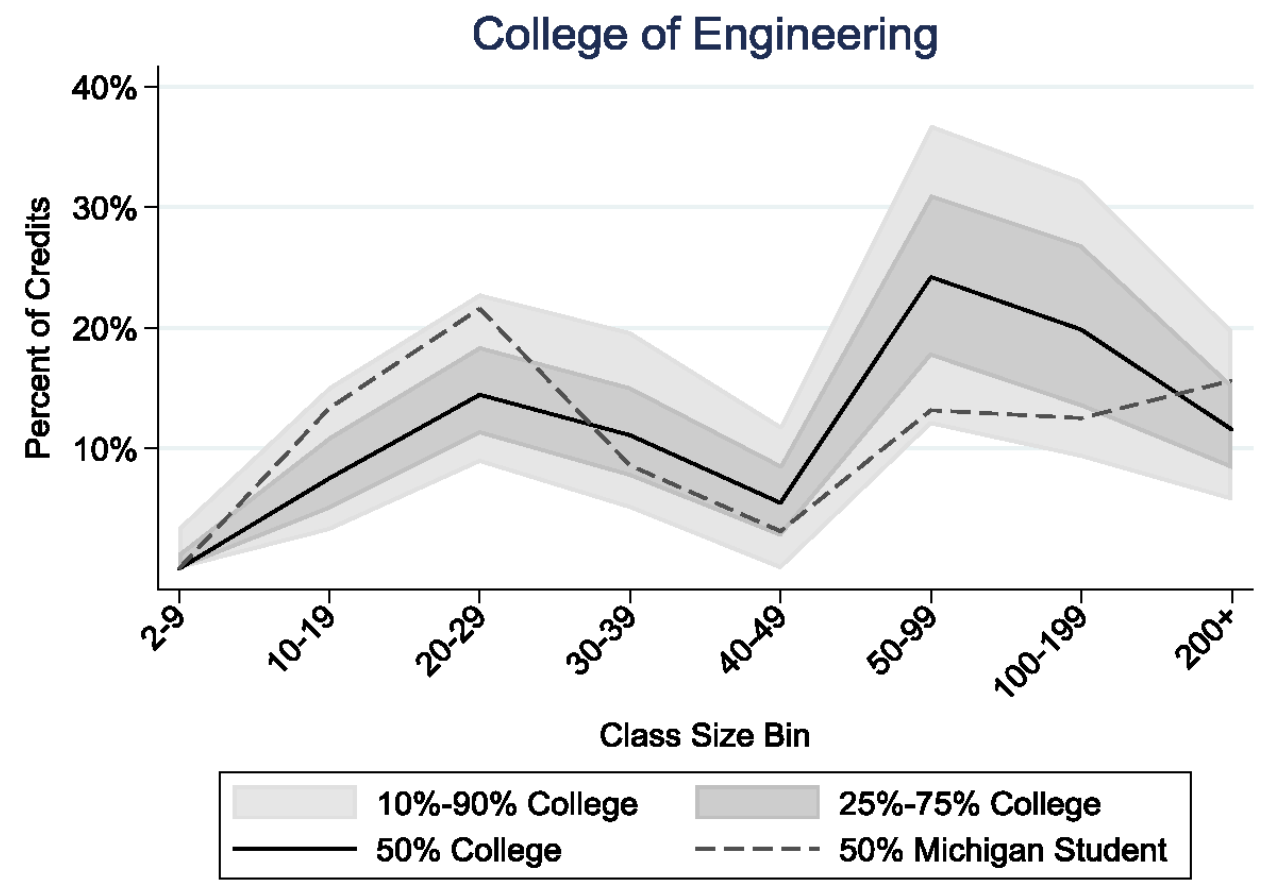

second-largest college on campus and differs significantly from the trends for the median student. Once again, the black line and gray shaded areas represent the percentiles for students in a given college. We added the gray dotted line here to show the median U-M student from Figure 2, allowing us to examine how the college differs from the overall pattern at the university. In the College of Engineering students tend to take coursework with very different class sizes compared to the median U-M student. In particular, engineering students take fewer small classes (10-29 students) and very large classes (200+ students), and instead take more classes in the middle range (30-199 students). Part of the difference could be attributed to deliberate planning by the College of Engineering and part could be related to the size of classrooms in the engineering buildings. Classroom caps, and subsequently enrollment caps, for classes in engineering tend to lie in the middle of the enrollment group distribution.

While not shown, we created figures for every college on campus. The trends of these figures show that class size differs significantly across colleges. The College of Literature, Science, and the Arts (LSA) has very similar trends to the median U-M student, in part because it is the largest college on campus. Given that more than $60 \%$ of students are in LSA, this college drives much of the median class size. As one would expect, smaller and more narrowly focused colleges such as the College of Architecture and Urban Planning, the College of Art and Design, and the College of Music, Theatre, and Dance had significantly higher levels of small classes (2-29 students) and fewer very large classes (200+ students). The College of Public Policy tends to mimic the trends of LSA, in part because students 
Figure 4. Class Size Within the College of Engineering by Academic Year

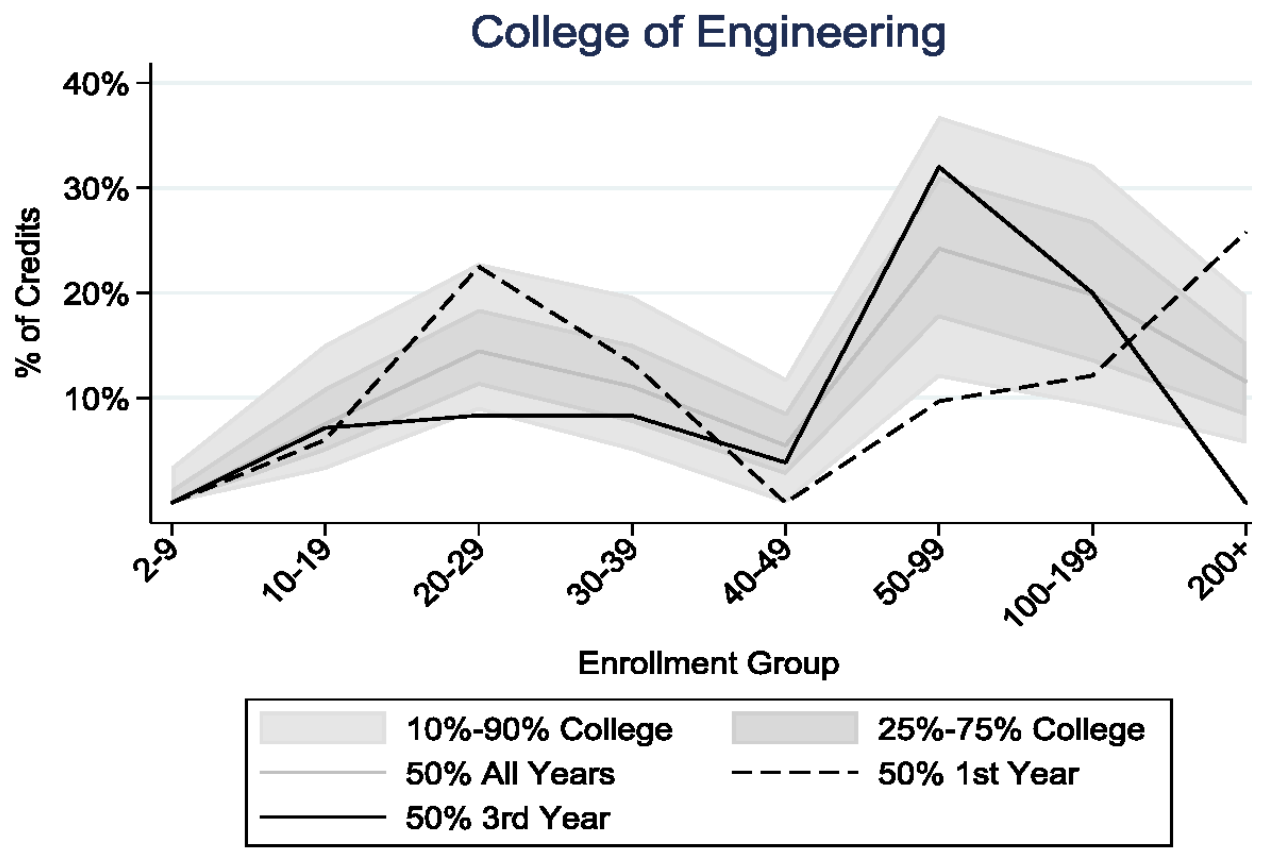

spend their first two years in LSA before declaring their major. The College of Business had very high levels of medium-size classes (40-99 students) because many of its core classes have enrollments of 40 to 80 students.

Class size also varies in systematic ways by major, even within a college. Comparing the major of Arts and Ideas in the Humanities, a small, multidisciplinary major, to the major of Biopsychology, Cognition, and Neuroscience (BCN), a large, premed major, yielded large differences in class size. The median Arts and Ideas major spent about 50\% of her time in classes with 20 or fewer students, which is twice the $25 \%$ of the median LSA student. Students in the BCN major, on the other hand, took a much larger share of large lectures, rising out of the 90th percentile for LSA students. They spent nearly 33\% of their time in classes with more than 200 students, compared to only 20\% of the median LSA student's time. While we observed systematic differences between majors, we also found that there were some majors that had very similar class size structures.

A final way to observe how class size varies across an institution is by comparing class size by academic level. Rather than aggregating across a college or major, we aggregated by a student's year in school (e.g., freshman, sophomore, junior, senior). Students in their first year typically fulfill their general education requirements, which tend to be classes taught to many students at once. By their junior or senior year, students tend to take many classes within their major of increasing depth and specialization, characterized by smaller class sizes. Splitting the data in this manner did yield interesting differences over time. As shown by the dotted line in 
Figure 4, students in the College of Engineering took similar coursework to LSA students in their first year compared to the median U-M student from Figure 2 , taking mainly classes consisting of large lecture and small discussion groups. This is likely because students are fulfilling their general education requirements. By their third year, the solid black line indicates the median engineering student deviates from the pattern at the college level and takes a much higher proportion of classes with 50-100 other students; these classes comprise classes in the students' major.

Overall, we created figures for every major, college, academic level, and student across campus to examine how class size varied across U-M. The median student within some majors had class size distributions that were very similar to the median student in their college and the university, but many majors differed significantly from the general trends. Similarly, there were some students within majors that varied significantly from the median student in their major. These figures show that class size can vary significantly across an institution. A department, college, or institution can use this information to gain a more nuanced understanding of the experiences of their students. For example, if students that tend to take only large lectures or small discussion classes perform worse, then an institution could adjust its advising to promote students to take classes of varying sizes. Similarly, an institution could identify whether certain student groups, such as first-generation students, may benefit from a more intimate classroom environment where they receive more attention from instructors.

\section{HOW SHOULD WE MEASURE CLASS SIZE?}

This paper has shown that the traditional measure of class size is not sufficient if it is meant to provide information about a student's actual experience in the classroom. Previous research has shown that increasing class size has a mixed but generally negative impact on student learning and satisfaction. Accurately measuring class size is also important to institutions because it impacts productivity. For example, increasing or decreasing the class size of introductory calculus, a class that most students on campus take, can have vast implications for the cost of the class. If an institution wanted to recalculate class size with the student experience at the core, what would it look like?

We will first consider two simple adjustments: weighting for credits and weighting for students. Table 2 shows the distribution of class size given four different calculations and Figure 5 provides a visual representation of the table. The first calculation is the traditional measure of class size, with no adjustments. This means there is one observation per lecture. The second column weights the traditional measure by number of credits. A class of four credits is now worth twice as much as a class of two credits. This slightly shifts the class size distribution down because large class sections have corresponding subsections. Consider a class worth three credits, two earned in a lecture and one earned in a lab. Since the lab, or subsection, is not counted in the traditional measure, one of the three credits is discarded, deflating the value of a large class. The third column accounts for subsections and credits, appropriately distributing all the credits associated with each class. A class worth three credits including a lecture and a lab, as described above, is now fully included in the metric for class 
Table 2. Class Size by Three Different Calculations

\begin{tabular}{c|ccccc}
$\mathbf{2}$ & $\begin{array}{c}\text { Traditional } \\
\text { Measures } \\
\text { Class Size }\end{array}$ & $\begin{array}{c}\text { Weight for } \\
\text { Credits } \\
\mathbf{( 1 )}\end{array}$ & $\begin{array}{c}\text { Account for } \\
\text { Subsections } \\
\mathbf{( 3 )}\end{array}$ & $\begin{array}{c}\text { Weight for } \\
\text { Students } \\
\mathbf{( 4 )}\end{array}$ & $\begin{array}{c}\text { Weight for } \\
\text { All Changes } \\
\mathbf{( 5 )}\end{array}$ \\
\hline $\mathbf{2 - 9}$ & $13.9 \%$ & $14.1 \%$ & $11.4 \%$ & $2.0 \%$ & $2.5 \%$ \\
$\mathbf{1 0 - 1 9}$ & $32.1 \%$ & $32.5 \%$ & $31.1 \%$ & $13.0 \%$ & $15.4 \%$ \\
$\mathbf{2 0 - 2 9}$ & $23.0 \%$ & $23.6 \%$ & $34.0 \%$ & $14.2 \%$ & $21.9 \%$ \\
$\mathbf{3 0 - 3 9}$ & $8.2 \%$ & $8.5 \%$ & $9.4 \%$ & $6.8 \%$ & $9.3 \%$ \\
$\mathbf{4 0 - 4 9}$ & $4.4 \%$ & $4.3 \%$ & $3.2 \%$ & $4.6 \%$ & $4.4 \%$ \\
$\mathbf{5 0 - 9 9}$ & $10.5 \%$ & $10.2 \%$ & $6.4 \%$ & $18.2 \%$ & $15.8 \%$ \\
$\mathbf{1 0 0 - 1 9 9}$ & $4.9 \%$ & $4.5 \%$ & $2.9 \%$ & $17.2 \%$ & $13.8 \%$ \\
$\mathbf{2 0 0 +}$ & $2.9 \%$ & $2.4 \%$ & $1.7 \%$ & $24.0 \%$ & $16.8 \%$ \\
\hline
\end{tabular}

size (Column 3). This lowers class size considerably because we are not removing the subsection but instead including it in our calculation. Subsections tend to be smaller, which drives the distribution down.

The fourth column shows class size distribution if we weighted only for the number of students in a class. Using this calculation, a large lecture of 500 students is counted 500 times, while a small class of 5 students is counted only 5 times. As expected, this dramatically shifts the distribution of class size upward, nearly flipping the distribution of class size from the traditional measure. Column 5 accounts for weighting by credits and students, and includes subsections simultaneously. This gets closer to the perfect measure of the student experience described earlier in this paper and vastly improves the understanding of class size for institutions and potential students. Figure 5 shows a visual representation of each strategy for calculating class size. We can see that the traditional measure (nonstudent experience), weighting for credits, and weighting for subsections are very similar, with slight increasing low enrollments (fewer than 30) and decreasing other enrollments (30-200+) after accounting for subsections. Once we weight for students there is an immediate shift, nearly flipping the distribution. However, this shift goes too far; accounting for credits and subsections provides a balance between the three strategies.

It is important to note that our calculation of class size used student-level micro data to account for these changes, in part due to other related research. However, this calculation may be burdensome for institutions. A simpler way to achieve the same results would be to take the class-level data used for 
Figure 5. Class Meeting Size Distribution by Five Different Methods

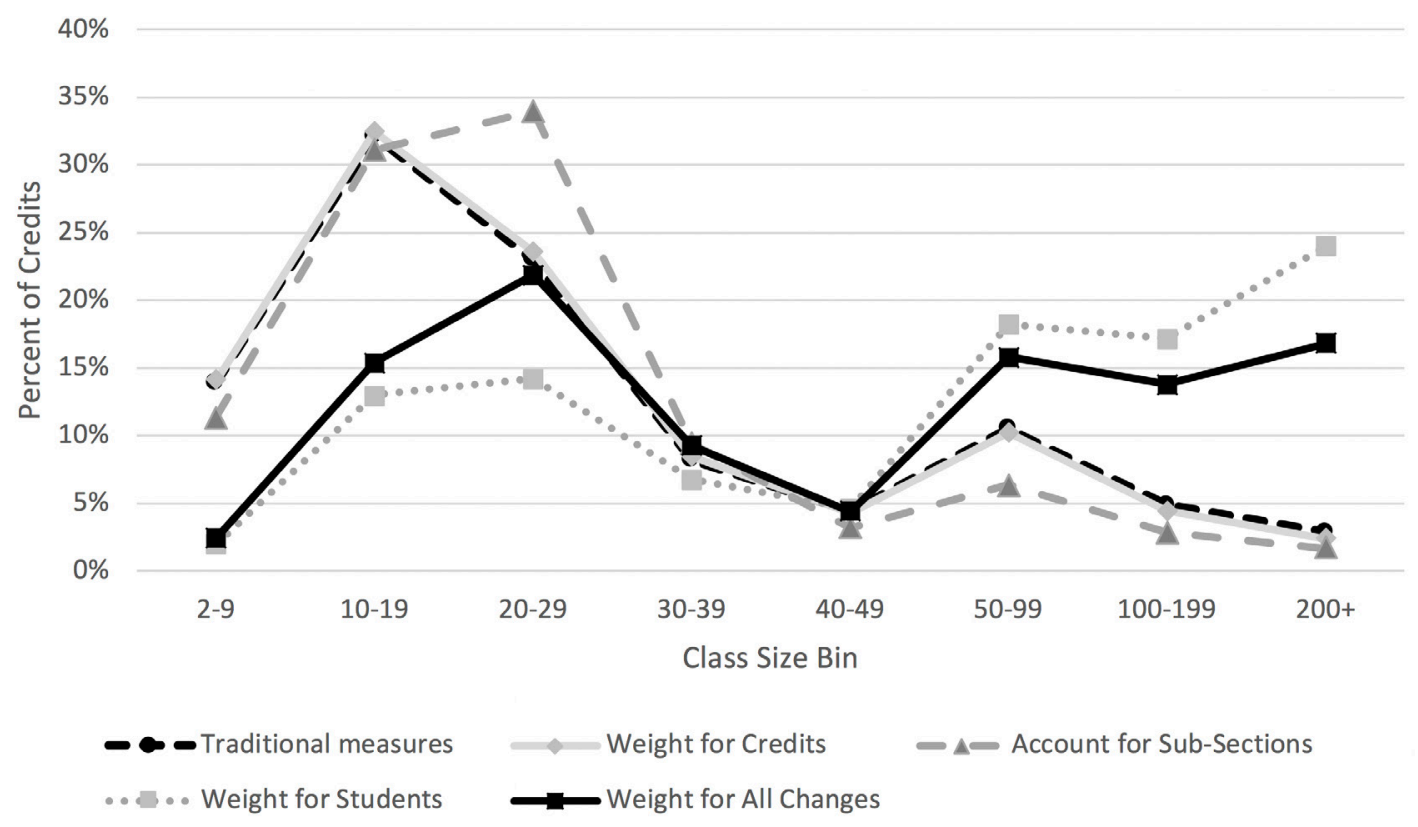

the CDS and simply weight each class section and subsection by the number of students and credits. This simplifies the process and limits the resources required to pull and process the data.

\section{LIMITATIONS OF NEW GLASS SIZE MEASUREMENT}

While this new class size metric may provide a clearer picture of the student experience at an institution, it does not come without limitations and challenges. The first challenge is the technical barriers of calculating the new class size measurement. For example, institutions may house the required variables in different data systems, but replacing or adding a new metric could be difficult to implement and could increase the reporting burden on institutions. Most of what is required to adjust to this new metric is already required for the CDS version of class size. Institutions must calculate the number of sections and subsections of a given class size. This means they must know the exact class size for every section and subsection. The only missing piece is to allocate time between the section and the subsection. At U-M, a field for distributed hours is contained in the data warehouse, but that may not be the case for all institutions, some of which may not even use the Carnegie credit system. For these institutions, a calculation could be made to allocate credits based on the amount of classroom time for each section and subsection. For example, a three-credit class that meets for 2 hours in a lecture section and 1 hour in a discussion section could split the class into two credits for the lecture and one 
credit for the discussion. This would require some up-front work to create these calculations based on day/time information, but is not unmanageable.

The second set of challenges relate to the nuance that is inherent in the new metric. Presenting students with a single metric for an entire university is simple and easy to explain but leaves out a lot of nuance. If an institution were to recreate the figures in this paper, it would introduce some challenges for interpretation. As shown in Figure 3, there are stark differences in class size between engineering and LSA students; the same differences can be shown between majors or year in school. The large number combinations and comparisons by college, major, and year in school present challenges when trying to show or explain the data to prospective or current students. While a single, institution-wide metric leaves out nuance, it is a vast improvement over the current metric used by institutions and rankings. If an institution wanted to provide more nuance, it could create an interactive dashboard for prospective and current students to view the nuanced version of class size presented in the figures of this paper. Students could select a college or major from a list to see what the distribution of class size looks like for students in that major. Institutions could pare down these figures to show only the median for simplicity or to provide a detailed explanation of how the percentiles work when students first use the new dashboard. However, with a nuanced view an institution could also show students that class size may be lower for a given major, or how class size may lower as students progress toward their degrees.

\section{DISGUSSION AND FUTURE WORK}

As institutional researchers it is imperative for us to provide data that are both accurate and meaningful. This paper argues that the traditional measure of class size is not a meaningful representation of what students experience in the classroom. The traditional measure of class size illustrates only the proportion of classes that are small, not the amount of time that students spend in small classes. This is problematic for prospective students, who could use meaningful class size data to determine where they want to attend college. It is also problematic for institutions, which may not understand the extent of large or small classroom experiences on their campuses. While limited, previous research in higher education suggests that class size matters for student outcomes and satisfaction in classes.

This paper suggests that the measurement of class size could be altered by weighting for the number of students and credits associated with the section, and accounting for subsections. We suggest that institutional researchers consider revamping their class size metric to reflect the student experience in the classroom more accurately. Nearly all the required components (number of students in each class and section/subsection, and number of classes) for this calculation are used by the current CDS metric. We believe that distributed credits, the potential missing component, is likely captured and readily available at many institutions, which would make this adjustment relatively easy. While this could require an investment of time on behalf of some institutions, we believe the potential benefits will outweigh the investment. At a minimum, we suggest that institutional research professionals consider reweighting their current metric of class size by the number of students in each lecture section. This new 
metric provides a more accurate description of class size from the student experience.

Future work on this topic could yield more improvements in the description of the student experience at institutions of higher education. First, the range of class size also varies significantly across colleges and departments, indicating that a simple institution-wide metric masks important differences for students who plan to major in different fields. Institutions could take this idea one step further to create an interactive dashboard that allows prospective and current students the opportunity to see the range of class size experiences for majors in which they have interest. A second improvement institutions could make would be to pair data about class size and instructor type (e.g., IPEDS instructor type). By combining the percent of time spent in varying class sizes and varying instructor types, students will gain a clearer picture of what their classroom experience would be at a particular institution.

\section{REFERENCES}

Angrist, J., \& Lavy, V. (1999). Using Maimonides Rule to estimate the effect of class size on scholastic achievement. Quarterly Journal of Economics, 114(2), 553-575. https://www.jstor.org/ stable/2587016?seq=1\#page_scan_tab_contents

Bernstein, S., Sauermelch, S., Morse, R., \& Lebo, C. (2015). Fundamentals and best practices for reporting Common Data Set (CDS) data. Presented at the Association for Institutional Research Annual Conference, Denver, CO, May 27.
Bettinger, E., Doss, C., Loeb, S., Rogers, A., \& Taylor, E. (2017). The effects of class size in online college courses: Experimental evidence. Economics of Education Review, 58, 68-85. https://doi. org/10.1016/j.econedurev.2017.03.006

Bettinger, E. P., \& Long, B. T. (2018). Mass instruction or higher learning? The impact of college class size on student retention and graduation. Education Finance and Policy, 13(1), 97-118. https://doi. org/10.1162/edfp_a_00221

Chetty, R., Friedman, J. N., Hilger, N., Saez, E., Schanzenbach, D. W., \& Yagan, D. (2011). How does your kindergarten classroom affect your earnings? Evidence from Project STAR. Quarterly Journal of Economics, 126(4), 1593-1660. https://doi. org/10.1093/qje/qjr041

Common Data Set (CDS) Initiative (2018). 20182019 Common Data Set Initiative. http://www. commondataset.org/

Courant, P. N., \& Turner, S. (forthcoming). Faculty deployment in research universities. In Hoxby, C. M. \& Stange, K. (Eds.) Productivity in higher education. Chicago: University of Chicago Press.

Cross, J. G., \& Goldberg, E. N. (2009). Off-track profs: Nontenured teachers in higher education. Cambridge, MA: MIT Press.

De Giorgi, G., Pellizzari, M., \& Woolston, W. G. (2012). Class size and class heterogeneity. Journal of the European Economic Association, 10(4), 795-830. https://onlinelibrary.wiley.com/doi/abs/10.1111/ j.1542-4774.2012.01073.x 
Dee, T. S., \& West, M. R. (2011). The non-cognitive returns to class size. Educational Evaluation and Policy Analysis, 33(1), 23-46. https://doi. org/10.3102/0162373710392370

Drewes, T., \& Michael, C. (2006). How do students choose a university?: An analysis of applications to universities in Ontario, Canada. Research in Higher Education, 47(7), 781-800. https://doi.org/10.1007/ s11162-006-9015-6

Dynarski, S., Hyman, J., \& Schanzenbach, D. (2013). Experimental evidence on the effect of childhood investments on postsecondary attainment and degree completion. Journal of Policy Analysis and Management, 32(4), 692-717. https://doi. org/10.1002/pam.21715

Espinoza, S., Bradshaw, G., \& Hausman, C. (2002). The importance of college choice factors from the perspective of high school counselors. College and University, 77(4), 19-23.

Hemelt, S. W., Stange, K. M., Furquim, F., Simon, A., \& Sawyer, J. E. (2018). Why is math cheaper than English? Understanding cost differences in higher education. Working Paper 25314, National Bureau of Economic Research, Cambridge, MA. https://doi. org/10.3386/w25314

Hoxby, C. M. (2000). The effects of class size on student achievement: New evidence from population variation. Quarterly Journal of Economics, 115(4), 1239-1285. https://doi. org/10.1162/003355300555060

Kokkelenberg, E. C., Dillon, M., \& Christy, S. M. (2008). The effects of class size on student grades at a public university. Economics of Education Review, 27(2), 221-233. https://doi.org/10.1016/j. econedurev.2006.09.011
Krueger, A. B. (1999). Experimental estimates of education production functions. Quarterly Journal of Economics, 114(2), 497-532. https://doi. org/10.1162/003355399556052

Lande, E., Wright, M., \& Bartholomew, T. (2016, October). Impact of smaller class sizes in U-M mathematics courses. Unpublished internal report, Center for Research on Learning and Teaching, University of Michigan, Ann Arbor.

Stange, K., \& M. Umbricht, 2018. Undergraduate class size reduction: Effects and costs. Unpublished working paper, University of Michigan, Ann Arbor.

Supiano, B. (2018, March 21). Are small classes best? It's complicated. Chronicle of Higher Education. https://www.chronicle.com/article/Are-Small-ClassesBest-It-s/242878

Wright, M., Bergom, l., \& Lande, E. (2015, September). Impact of smaller class sizes in U-M Spanish and German courses. Internal report, Center for Research on Learning and Teaching, University of Michigan, Ann Arbor. Executive summary at http://crlt.umich.edu/sites/default/files/ SmallClassExecSum.pdf 